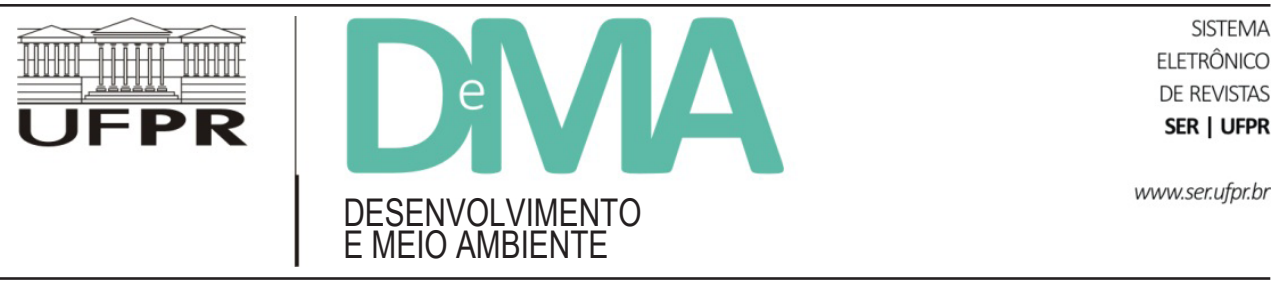

\title{
Alteridade e ato responsável em Bakhtin e Lévinas: contribuições à educação ambiental inspirada pelo infinito ético
}

\section{Alterity and Responsible Act in Bakhtin and Lévinas: Contributions to Environmental Education Inspired by the Ethical Infinite}

\author{
Ítalo César de Moura SOEIRO ${ }^{*}$, Marina Assis PINHEIRO², Diana Carolina Gómez BAUTISTA ${ }^{1}$ \\ ${ }^{1}$ Programa de Pós-Graduação em Desenvolvimento e Meio Ambiente (PRODEMA), Universidade Federal de Pernambuco (UFPE), Recife, \\ PE, Brasil. \\ ${ }^{2}$ Programa de Pós-Graduação em Psicologia Cognitiva, Universidade Federal de Pernambuco (UFPE), Recife, PE, Brasil. \\ *E-mail de contato: italosoeiro@gmail.com
}

Artigo recebido em 17 de agosto de 2016, versão final aceita em 4 de abril de 2017.

RESUMO: A crise ambiental exige uma reflexão crítica sobre as suposições que orientam a sociedade ocidental moderna. Ao abandonarem a concepção da Natureza enquanto forma de vida orgânica e autodeterminada e, assim, passando a concebê-la como objeto a ser dominado, retiram-na do interior das relações éticas. Buscando um diálogo entre as noções de ato responsável e alteridade em Mikhail Bakhtin e Emmanuel Lévinas, respectivamente, a reflexão ética abordada neste ensaio problematiza como essas categorias podem ultrapassar a relação humano-humano, no sentido de uma responsabilidade com o Outro não humano que é subjetivado na e pela cultura, o que pode ser representado pela ideia_da transcendência do 'si mesmo' em direção ao Infinito Ético. Assim sendo, o objetivo deste artigo é o de contribuir para o universo da Educação Ambiental, aproximando a abordagem da Natureza à alteridade/diferença inerente ao ato responsável e colocando-a como um Outro que deve ir muito além das gramáticas da dominação/servidão.

Palavras-chave: Bakhtin; Lévinas; natureza; crise ambiental; ética.

ABSTRACT: The environmental crisis requires a critical reflection concerning the assumptions that guide modern Western society. In abandoning the conception of Nature as an organic and self-determined form of life, and thus conceiving it as an object of domination, Nature is thus subtracted from ethical relationships. The approach that inspires our understanding of ethical crisis in this paper discusses how the categories of responsible act and alterity in Mikhail Bakhtin and Emmanuel Lévinas, respectively, can surpass the relationship human-tohuman, reaching new ways of responsibility that could include the relationship between human to the other non-human, which is also recreated by culture. Therefore, the purpose of this article is to contribute to the field of environmental education through an approximation of the concept of Nature to the core sense of alterity/ 
difference inherent to the responsible act towards the ideal of ethical infinite. Nature must be placed as an Other that should go further beyond domination/servitude grammars.

Keywords: Bakhtin; Lévinas; nature; environmental crisis; ethics.

\section{Introdução}

Nos séculos XVI e XVII, a noção de um Universo orgânico, vivo e espiritual foi sendo enfraquecida pela emergência de suposições vinculadas à física, à astronomia e à matemática. Nessas suposições, o mundo passa a ser concebido e narrado como uma máquina. A "máquina do mundo" tornou-se, assim, a metáfora dominante da modernidade, e sua inércia é profundamente sentida ainda na atualidade das relações éticas do humano frente ao humano e do humano frente ao não humano. ${ }^{1}$ Nesse sentido, as noções de ética e de natureza foram desenhadas e aparelhadas ao longo dos séculos, de forma a impossibilitar qualquer reconciliação, qualquer síntese ou combinação entre os dois termos. No entanto, a visão do Universo como um sistema mecânico, do corpo humano como uma máquina, da sociedade como uma luta competitiva pela existência e da crença no progresso material ilimitado da Natureza, a ser obtido por intermédio de crescimento econômico e tecnológico, têm sido desafiada por eventos recentes, relacionados à crise ambiental (Capra, 2006).

A expansão da Ecologia Política - movimento que proclama a necessidade da irrupção da natureza na política, modificando a vida pública - pode ser tomada como exemplo das reações, nas esferas ético-acadêmica e político-econômica, da crise ambiental. Em sua dimensão paradoxal e utópica, a ecologia política pretenderia até mesmo adaptar nosso sistema de produção às exigências da natureza, a fim de conservar a natureza contra as degradações humanas. Porém, para que logremos isso, deve-se, como alerta Latour (2004 p. 13):

Muito longe de ultrapassar as dicotomias do homem e da natureza, do sujeito e do objeto, dos sistemas de produção e do ambiente, a fim de encontrar o mais rapidamente possível os remédios para a crise, era preciso, ao contrário, diminuir o movimento, tomar seu tempo, suspendê-lo, depois descer abaixo destas dicotomias para cavar como a velha toupeira.

De fato, uma parcela dos pensadores das questões ambientais - Leff $(2001 ; 2012 ; 2012)$, Capra (2006), Morin (1999; 2013) - está promovendo, na atualidade, uma revisão radical dessas suposições em que se embasam a sociedade ocidental, pois estas se pautam em um modo de ver o Universo que é centralizado no ser humano. Uma ética que "vê os seres humanos como situados acima ou fora da natureza, como a fonte de todos os valores, e atribui apenas um valor instrumental, ou de 'uso', à natureza." (Capra, 2006, p. 25).

Nesse sentido, é propósito do presente artigo desenvolver uma reflexão sobre a função da alteridade, da responsabilidade e do agir ético, num sentido mais amplo, como forma de perspectivar uma paisagem hermenêutica para a natureza, dis-

\footnotetext{
${ }^{1}$ A relação do humano frente ao não humano é um ponto importante para discussão proposta. O termo não humano pode gerar certa estranheza para o leitor. Na perspectiva do dialogismo, tudo que reconhecemos como sendo propriamente "humano" seria constituído, co-geneticamente, por uma diferenciação em relação - não à Natureza, enquanto categoria reflexiva abstrata fechada - mas sim, em relação à abertura própria do universo indeterminado, negativo, aberto e incompleto do "não humano". Desta forma o uso do termo não humano é também uma tentativa de evitarmos os problemas conceituais inerentes à noção de Natureza, debate esse que não é objeto desta escrita.
} 
tinta das gramáticas objetificantes da realidade. À luz do dialogismo bakhtiniano e da obra de Lévinas, a serem apresentadas mais adiante no texto, almeja-se provocar uma interlocução junto à Educação Ambiental, ${ }^{2}$ enquanto campo necessário à transformação dos jogos de linguagem tradicionais sobre os modos de agir/pensar sobre a alteridade da Natureza, ou ainda, sobre a relação do humano frente ao não humano.

Muitas são as bases apontadas pelos estudiosos como responsáveis pela atual configuração ética do humano frente ao mundo. Primeiramente, traz-se, entre outras, a tradição judaico-cristã, pois esta tem fundamental contribuição para o enraizamento desse modo ocidental de conceber o Universo, ou seja, nessa exteriorização do humano. Para tanto, consideramos fundamental, para compreender o papel da doutrina cristã em tal enraizamento, entender suas teorias sobre o Universo e o homem. O ponto fundamental de sua teoria do Universo é a existência de Deus. Stevenson (1976, p.51), ao discutir tal conceito para o cristianismo, afirmou que:

O Deus cristão não é considerado um objeto entre outros no universo; não ocupa nem posição no espaço nem dura um determinado período temporal. Não é tampouco identificado como todo o universo, soma de tudo que existe [...] Isto é panteísmo e não cristianismo.
Em relação à teoria do homem, tal concepção o vê basicamente na sua relação com esse Deus que o criou para "que ele ocupasse uma posição especial no universo." (1976, p. 55). O homem, assim, foi feito à imagem e semelhança de seu criador, para ter domínio frente ao resto da criação. "[...] é um ser único no sentido de que tem em si algo da autoconsciência e da capacidade de amar que é próprio de Deus" (1976, p.55). Ramos (2010, p. 75), ao discutir a contribuição desse paradigma para o entendimento da crise ambiental, afirmou que:

No pensamento antigo, a natureza sempre existiu e sempre teria existido. Ela era o todo, e não algo que estava na dependência do arbítrio de Deus. No pensamento judaico-cristão, ao contrário, o homem não se situa na natureza, mas perante ela, e o seu destino é concebido independentemente da história do mundo, como um elemento fora de um conjunto. O ser humano é considerado transcendente em relação ao mundo físico, não pertence à natureza, mas à graça, que é sobrenatural [...].

Por outro lado, apesar de o homem, na concepção judaico-cristã, ser visto como um ente fundamentalmente distinto do resto da criação, ele está, ao mesmo tempo, em continuidade com ela. "Ele é feito do pó da terra [...], ou seja, é matéria." (Stevenson, 1976, p. 55). Percebe-se, então, a presença de um dualismo, no qual o homem é, ao mesmo tempo, exterior e contínuo com o "resto"

\footnotetext{
2 Torna-se importante destacar que, no argumento do presente artigo, a Educação Ambiental é convocada não enquanto um objeto de análise em si mesma. Quando aludimos à função da interlocução junto a esse campo de saber, tal diálogo é proposto com vistas a uma problematização que vai para além de suas práticas educativas particulares, ou ainda, de seus regimentos legais contemporâneos, a exemplo do artigo $4^{\circ}$, que versa sobre os princípios básicos da Educação Ambiental (Lei n ${ }^{\circ}$ 9.795/99). A discussão do presente trabalho assume muito mais um recorte epistêmico, histórico, axiomático, ético do que uma análise empírica do vasto e multicultural campo de saber-fazer da Educação Ambiental. Dessa forma, como citado anteriormente (Latour, 2004), a Educação Ambiental se insere enquanto universo transformador dos modos de conceber a relação humano e não humano e que, por esse motivo, se configura como interlocutora necessária à argumentação proposta. A discussão de cunho mais empírico das práticas e leis que regulam a Educação Ambiental à luz do princípio ético da responsabilidade e alteridade requereria a pesquisa e escrita de outro ensaio, a ser delineado futuramente. Destacam-se alguns estudos que assumem esse foco mais analítico e empírico, a saber: Sorrentino et al. (2005), Tristão (2004) e Muñoz (1996).
} 
da criação/Natureza. Porém, a noção de exterioridade do homem irá se acentuar com a penetração das filosofias gregas (principalmente platônicas) na formulação de sua doutrina, por exemplo, na concepção de alma imaterial,ficando assim, bastante esclarecido que essa concepção de homem externo em relação à "Natureza/criação" foi de grande importância para a formulação ocidental de exterioridade da humanidade.

A filosofia de Descartes, por sua vez, enquanto mais uma das bases da modernidade, representa, em certos aspectos, o auge das tentativas de diferenciar o humano dos demais seres do Universo. "Em sua filosofia, apenas o corpo humano se encontra dentro da Natureza, como alguma coisa que não é sagrada; o que fica fora da Natureza é unicamente a consciência.” (Passmore, 1995, p. 94). Todavia, o humano, associando espírito e corpo, coloca-se em oposição total com o mundo não humano. Assim, o dualismo cartesiano foi utilizado para justificar a ideia de que o ato do humano não era sujeito a nenhuma restrição moral frente ao mundo não humano, já que apenas o humano é dotado de consciência (Passmore, 1995).

A filosofia ocidental foi, na maioria das vezes, uma ontologia: uma redução do Outro ao Mesmo, pela intervenção de um termo médio e neutro que assegura a inteligência do ser. O primado do Mesmo foi a lição de Sócrates: nada receber de Outrem a não ser o que já está em mim, como se, desde toda a eternidade, eu já possuísse o que me vem de fora. (Lévinas, 2000, p. 31).

As suposições basilares da sociedade moderna ocidental, no contexto de crise ambiental, estão sendo questionadas e criticadas. Isso porque, ao abandonarem a concepção da Natureza enquanto algo vivo e orgânico, passando a concebê-la como objeto a ser dominado e a serviço da ideia de progresso, retiram-na do interior das relações éticas.
Críticas que derivam do fato de que a maioria de nós, e em especial nossas grandes instituições sociais, como afirma Capra (2006), corroboram os conceitos de uma visão instrumental do mundo, do fortalecimento da cosmo-ontologia do ser e do ente e de uma percepção da realidade inadequada para lidarmos com sua complexidade. Porém, o que mais nos assusta é o estado do mundo, que,

partiendo de la denominación de lo real, llega al congelamiento de sus significados; no tanto por un agotamiento de la significancia del lenguaje, sino por la codificación del mundo bajo el signo omnipresente, omnipotente y ominoso de la ley económica. (Leff, 2003, p. 14).

Portando, vivemos uma crise da percepção, do conhecimento, da economia política, da ecologia, da ética, ou seja, uma crise ambiental, como alerta Leff (2003, p. 14), em que:

El ecologismo es el último intento por recuperar la unidad de ese mundo resquebrajado, fundado en ese mito de origen anclado en la metafísica, que, con la disyunción entre el ser y el ente, inicia la odisea del mundo occidental, aventura civilizatoria que llega a su límite con la crisis ambiental: crisis de la naturaleza en tanto que degradación del ambiente, pero sobre todo, crisis del conocimiento que sólo es posible trascender rompiendo el cerco de la mismidad del conocimiento y su identidad con lo real fundado en el imaginario de la representación, abriéndose al infinito desde un diálogo de saberes en el encuentro del Ser con la Otredad.

Nesse contexto, os críticos ecológicos da civilização ocidental almejam uma nova ética, uma nova estética e uma nova metafísica; um outro da civilização em que vivemos, um outro, enfim, tão desconhecido quanto desejado/intuído. Como afirma Passmore (1995), a metafísica ocidental e a ética têm contribuído para o encorajamento da exploração da Natureza. 
Essas críticas às bases da modernidade são elaboradas, sobretudo, seguindo o caminho da economia política e/ou ético-moral. Porém são críticas que, em sua maioria, permanecem antropocêntricas, ou seja, permanecem, direta ou indiretamente, associadas a uma tese ética defendida fortemente pelos Estoicos e por Agostinho: que nenhuma consideração de ordem moral embasa as relações dos humanos com os seres não humanos, exceto em que tratá-los destrutivamente poderia refratar ou refletir negativamente contra o humano, como afirmara Passmore (1995). Em outras palavras, o ato cruel para com o Outro não humano é errado apenas em virtude de seus efeitos nocivos ao Eu mesmo ou a Outro humano.

O presente artigo, por sua vez, acomoda-se sob a corrente ético-moral, mas consciente de que a problemática ambiental que vivemos extrapola essa dimensão. Como alertara Thomas (2010), esse “espírito ocidental contra a natureza" não é fruto apenas da visão de mundo oriunda da tradição religiosa judaico-cristã, como propôs o professor Lynn White Jr. (1967) ao descrever o cristianismo, em sua forma ocidental, como "the most anthropocentric religion the world has ever seen" (p. 1205). O surgimento da propriedade privada e da economia monetária perpetua uma noção de "natureza" promotora de um dos pilares do capitalismo combatente da deificação da Natureza. Sendo assim, podemos afirmar que o cristianismo "made it possible to exploit Nature in a mood of indifference to feelings of natural objects" (p. 1205), porém, esseespírito ocidental contra a natureza não se deve apenas a uma postura ética fruto da religião, pois, como exemplifica Thomas (2010, p. 31), “[...] o culto à natureza não evitou a poluição no Japão". Mesmo sendo uma crise complexa, acreditamos na existência de soluções para os principais problemas de nosso tempo, porém, são sempre soluções que requerem uma mudança radical em nossas percepções, no nosso pensamento e nos nossos valores (Capra, 2006). Essa mudança pode ser encarada por muitos como utópica, pois, tendo em vista os obstáculos epistêmicos, econômicos e éticos que se apresentam como uma inércia da modernidade, a passagem para um Infinito ético - em que a alteridade e o ato responsável sejam categorias fundamentais na nossa relação com o Outro humano e não humano - aparenta ser inalcançável.

Cabe destacar que a ideia de Infinito que estamos referenciando aqui apresenta-se no contexto léviniano, e tal ideia tem a função de servir como categoria para a relação entre o Eu mesmo e o Outro, sustentando a exterioridade dos interlocutores e propondo uma transcendência do 'si mesmo' sem que a totalidade simplifique a presença do 'outro em mim'. Destaca-se aqui, como adverte Pelizzoli (1994), que a transcendência própria à ideia de Infinito sugere não uma transcendência ao modo das religiões, mas enquanto deslocamento/descentração/exotopia em direção ao outro. Nas palavras de Lévinas (2000, p. 35-36):

O ser cognoscente permanece separado do ser conhecido. A ambiguidade da evidência primeira de Descartes que revela, sucessivamente, o eu e Deus sem os confundir, revelando-os como dois momentos distintos da evidência que reciprocamente se fundamentam, caracteriza o próprio sentido da separação. A separação do eu afirma-se assim, como não contingente, como não-provisório. [...] a transcendência filosófica difere assim da transcendência das religiões [...] Pensar o infinito, o transcendente, o Estrangeiro, não é pois pensar um objeto.

É, portanto, uma relação sem correlação precedente à intencionalidade objetiva, mantida com aquele que não posso conter, com o que está separado. Assim, a ideia de Infinito supõe a separação do Mesmo em relação ao Outro, mas tal separação 
não pode se assentar numa oposição ao Outro, que seria antiética.

Buscando um diálogo entre as noções de ato responsável e alteridade em Mikhail Bakhtin (2010a; 2010b) e Emanuel Lévinas (2000; 2005), respectivamente, assim como em outros autores (Leff, 2003; Pelizzolli, 2002; 2003; Sobral, 2005; Sampaio, 2009; 2011; Ponzio, 2008; 2010; Amorim, 2009; Souza, 1999; Zavala, 2009) que auxiliaram nessas leituras, a reflexão ética trazida neste artigo vem problematizar em que medida essas categorias podem e devem ultrapassar a relação humano-humano, na qualidadede uma responsabilidade com o Outro não humano. Ou seja, uma alteridade que nos leve em direção ao Infinito ético. Portanto, o horizonte ético que aqui será reforçado preza pela busca de uma relação responsável na assimetria das alteridades dos seres humanos e dos não humanos, o que implica, segundo Carvalho et al. (2011), o reconhecimento do valor não utilitário da Natureza e dos direitos dos não humanos. Esses, para nós, só poderão ser alcançados por intermédio de uma Educação Ambiental do ato responsável com esse Outro humano e não humano. Alerta-se, porém, que não se deve conceber como de inteira responsabilidade da Educação Ambiental o ultrapassar dos obstáculos éticos que se oferecem como inércia dos preceitos modernos, pois é necessário que percebamos que ela sozinha também é insuficiente, precisa de cooperação. Como sabemos, não vivenciamos uma crise apenas ética, mas epistêmica e econômica, ou melhor, civilizatória.

Assim sendo, o objetivo deste artigo é contribuir, à luz da reflexão proposta, para uma Educação Ambiental que maximize a aproximação da abordagem da Natureza ao conceito de Outro, conectando-a à categoria da alteridade, colocando-a como um Outro que deve ir muito além dos jogos de linguagem da dominação, como propusera Peliz- zoli (2003), que a descreve como portadora de vida própria e que deve ser acolhida em sua dignidade.

O leitor pode estar indagando sobre o porquê de convocar autores de filosofias aparentemente incomensuráveis na mesma reflexão sobre a alteridade não humana no contexto da argumentação proposta. Que contribuições poderiam ser construídas a partir de uma interlocução entre Bakhtin e Lévinas? Ainda que alguns poucos pesquisadores (Nealon, 1997; Eskin, 2000; Erdinast-Vulcan, 2008; Sampaio, 2012; Bøeet al., 2013) já tenham buscado um diálogo entre ambos, retoma-se a relevância de articular gramáticas distintas sobre a alteridade numa forma de uso que exercite uma imersão em suas diferenças e aproximações. Alertamos, porém, que essa proposta de diálogo entre os filósofos não é arbitrária e tampouco aleatória, uma vez que a fazemos cientes das diferenças entre os autores. Contudo, ambos demonstram uma preocupação expressivamente ética em suas obras. De um lado, Lévinas, que discute a alteridade diretamente vinculada à filosofia, por meio, sobretudo, de suas críticas à totalidade do ser e de sua busca pela reconstrução da externalidade do Outro transcendendo a textura ontológica do Eu mesmo. De outro lado, Bakhtin, vinculado à crítica literária e escrevendo-a tentando dar conta sobre como se dá o ato criativo numa consciência que é alienada e constituída pela voz do Outro.

Na crise ética contemporânea, torna-se necessário convocar os autores que se debruçaram sobre o princípio da não identidade do si mesmo e da ética da diferença, pois, como alerta Sampaio (2012), a dimensão ética, em ambos os autores, sugere um novo paradigma de pensamento e de ação, oportunizando um novo olhar acerca da alteridade e suas formas de expressão, além de oferecer importante contribuição para se pensar o papel do sujeito, da subjetividade e da intersubjetividade nas relações do humano com o humano e com o não humano. 
Nesse sentido, a educação enquanto uma ação voltada para o futuro (mas que se efetua num presente evanescente e num passado infinito) precisa dialogar com a filosofia engajada no ser e no que o extrapola para autorar novas modalidades hermenêuticas da relação do humano com o não humano. Para tanto, visando à realização da discussão ora proposta, este texto foi estruturado para abordá-la da seguinte forma: na próxima seção, o texto apresentará as noções de alteridade, ato responsável e Infinito Ético por meio das leituras de Lévinas e Bakhtin. Na terceira e última seção, propomos algumas considerações a fim de explanar como as proposições desses filósofos podem ajudar na formulação de uma Educação Ambiental que exprima o sentido ético do existir humano, enquanto possibilidade de edificação de sua identidade na aventura da abertura infinita e responsável para o Outro.

\section{Infinito Ético, Alteridade e Ato Responsável em Lévinas e Bakhtin}

Antes de realizarmos uma imersão nas categorias Alteridade, Ato Responsável e Infinito Ético em Lévinas e Bakhtin, faz-se necessário apontar, ainda que brevemente, a contingência histórica de que os autores aqui estudados estavam participando. Tais contextos ideológicos, sociais e epistêmicos são importantes indicações para o entendimento das gramáticas culturais e simbólicas que cunharam suas criações intelectuais.

\subsection{Lévinas}

Emmanuel Lévinas, de origem judaica, nasceu em janeiro de 1906, na cidade de Kaunas, na Lituânia. Após a primeira guerra mundial, a Lituânia ficou em zona de fronteira, motivo que levou a sua família - comerciantes judeus - a abandonar provisoriamente sua pátria para fugir para Ucrânia. Já nesse novo país, surpreendem-lhes a Revolução de outubro de 1917, de tal modo que tiveram que regressar a sua pátria, que já havia se constituído em Estado. Em 1923, Lévinas vai viver em Estrasburgo, a cidade francesa mais próxima da Lituânia, e inicia seus estudos de filosofia. Lévinas atribui sua vocação filosófica ao forte impacto da leitura dos clássicos russos ao abordarem as questões sobre o sentido da vida. Em especial, Dostoyevsky e Shakespeare são amplamente citados em suas obras; ainda que não faltem alusões a Gogol, Tolstoi, Moliere e Cervantes (Vial, 1996). Porém, muito mais importantes que a leitura desses clássicos é sua formação nas tradições judaicas e o estudo da Bíblia. Talvez, por isso, Lévinas vai refletir, sobretudo, acerca das temáticas vinculadas ao político-religioso e ao filosófico-ético. Outra peculiaridade que cabe destacar se refereao sofrimento e ao terror impostos aos seus familiares, amigos e a ele mesmo pela chegada do nazismo, da perseguição aos judeus e da guerra (Pelizzoli, 2002).

No que concerne aos seus estudos filosóficos, já na cidade de Estrasburgo-França, foi aluno de Edmundo Husserl. O contato com um dos maiores expoentes da fenomenologia possibilitou a Lévinas utilizar-se de um instrumental desse método filosófico. Nesse contexto, é frequente o uso em suas obras da descrição fenomenológica, de termos como 'fenomenologia da sensação como gozo', 'intencionalidade encarnada', 'consciência de', o que nos inclina a considerar esse seu traço em nossas interpretações.

Mais tarde, vai seguir a produção de Heidegger, que, por sua vez, afetou profundamente o pensamento léviniano com a obra o Seinund Zeit (Ser e o tempo), como demonstrara Sampaio (2012). A visitação crítica e, por vezes, radical da 
obra heideggeriana pode ter explicação para além da filosofia, pois Lévinas não anistia o pensador alemão na questão do nazismo. No entanto, esse descontentamento referente a tal temática permitiu um nível de seriedade analítica assustadora, como observado em "Totalidade e Infinito" (2000), em que quase que questão por questão das temáticas do "Ser e o Tempo" são atingidas. Lévinas, portanto, reconhece o potencial analítico-existencial e hermenêutico da filosofia de Heidegger, porém, vai desconstruir as bases de sua filosofia que produziram o auge da ontologia ocidental, no que respeita à totalização do Eu mesmo sobre o Outro.

A crítica mais aguda de Lévinas à produção de Heidegger pode ser compreendida à luz dessa contingência geopolítica, à luz da qual acusa a ontologia heideggeriana de viabilizar, filosoficamente, um Estado totalitário e tirano, "pois a ontologia como filosofia primeira é uma filosofia do poder. Desemboca no Estado e na não-violência da totalidade, sem se presumir contra a violência de que vive essa não-violência e que se manifesta na tirania do Estado" (Lévinas, 2000, p. 33). Lévinas esclarece tal declaração afirmando que a ontologia heideggeriana,

É certo que a liberdade, a que a essência da verdade recorre, não é, em Heidegger, um princípio de livre arbítrio. A liberdade surge a partir de uma obediência ao ser: não é o homem quem detém a liberdade, mas a liberdade que detém o homem. Mas a dialéctica que concilia assim a liberdade e a obediência, no conceito de verdade, supõe a primazia do Mesmo, a que conduz a toda a filosofia ocidental e pela qual ela se define. [...] A relação com o ser, que actua como ontologia, consiste em neutralizar o ente para o compreender ou captar. Não é, portanto, uma relação com o outro como tal, mas a redução do Outro ao Mesmo. [...] A tematização e a conceptualização, aliás inseparáveis, não são paz com o Outro, mas supressão ou posse do Outro. 'Eu penso' redunda em 'Eu posso'. (Lévinas, 2000, p. 33).
Foi, portanto, a partir dos anos 50 que o autor passou a formular suas próprias ideias acerca da relação ética com o Outro. Reclama uma volta às coisas mesmas, pois, para o filósofo, uma filosofia moral efetiva deve pressupor uma experiência moral que ultrapasse a fenomenalidade. Portanto, o autor apela ao que ficou conhecido como metafenomenologia ou meta-ontologia, ou seja, uma "externalidad (lo obsolutamente Outro) del conocimiento objetivo que busca la mismidad entre la palabra y la cosa, la identidad entre el concepto y lo real, el reflejo del ente en el conocimiento" (Leff, 2003, p. 21).

Para lograr a proposição da externalidade e da transcendência do Mesmo, Lévinas (2000) concebe a noção filosófica do Infinito ético.É por intermédio dessa categoria que vai buscar sair da totalidade - identificação da subjetividade e consciência -, apontando a necessidade de a subjetividade se afastar do fechamento em si mesma. Como elucida Rodrigues (2012, p. 167-167):

\begin{abstract}
Ele ensaia um caminho por onde é possível a verdadeira aventura do Eu, ou seja, uma saída para o mundo sem retorno. Ele acredita que a Ideia do Infinito contrária à ideia de Totalidade aponta para o mais além do Ser, ou melhor, a Ideia do Infinito é a tese que vai romper com a Totalidade do Ser, pois é tal Ideia “[...] que explode a quadratura ontológica da totalidade de sentido e significado do mundo.
\end{abstract}

É a partir do Infinito Léviniano que chegaremos às noções de alteridade e responsabilidade, pois a ideia de Infinito nos mostra a necessidade de extrapolar a ontologia do Eu mesmo e ir em direção à exterioridade, ao Outro. Com isso, Lévinas (2005) demonstra que há algo para além do Ser, e mesmo que meu pensamento não possa abarcar o Outro, ele existe e está além dos caprichos subjetivos do Eu mesmo, e muito além da trama da ontologia e da consciência de si, como destaca Rodrigues (2012). 
Assim sendo, Lévinas reconstrói a exterioridade do Outro, a qual a filosofia da autonomia deslembra ou restringe ao Eu mesmo.

Se Heidegger elabora uma filosofia que desarraiga da metafísica e se constitui como ontologia auto-suficiente, retirando o ser do esquecimento em que tombara na filosofia ocidental, Lévinas, por sua vez, aventura-se a dar um novo passo: desarraigar-se das amarras ontológicas para libertar o homem, constituir a ética como filosofia primeira sobre a relação absoluta da alteridade. (Pivatto, 2005, p. 12-13).

Se Heidegger encontra a raiz do mal-estar da cultura ocidental na ruptura entre o ser e o ente, Lévinas acusará uma problemática de raízes mais profundas: a da constituição do ser humano pela linguagem, como alertara Leff (2003). Dessa maneira, recupera-se um sentido ético capaz de abalar os alicerces ontológicos do pensamento que aproxima e prende o ser na objetividade de um presente sem transcendência. Como afirma Lévinas, "el conocimiento objetivo, aunque siga siendo desinteresado, no por ello deja de estar marcado por el modo en el ser cognoscente ha abordado lo Real." (1997, p. 87-88). É preciso, assim, pensar o Outro de maneira que o pensado continue exterior ao pensamento que o pensa.

La relación de otredad no es una de referencia con lo real, de trascendencia del Ser o de transferencia con un gran otro. La relación de otredad no es la que se establece en la polaridad que produce el pensamiento metafísico en la dualidad mente-cuerpo, sujeto-objeto, unidad-diversidad. La relación con lo otro se da en el orden del ser y del saber; pero sobre todo es diferencia, relación ética con el otro humano y no una relación ontológica, epistemológica o fenomenológica. (Leff, 2003 p. 21).

A armadura teórica oferecida por Lévinas, que introduz uma relação ética, anterior e mais além de toda ontologia e toda epistemologia, deve ser reforçada na Educação Ambiental, pois sua forma de compreensão do mundo abriu um caminho em direção da constituição de uma história balizada numa relação ética do Ser com o Outro.

\subsection{Bakhtin}

Mikhail Bakhtin (1895-1975), por sua vez, nascido na cidade de Orel, próxima a Moscou-Rússia, formou-se em História e Filologia em 1918. Segundo Tzvetan Todorov (2011), foi um filósofo e um pensador que, em seus escritos, abarcou, ao lado da linguística, da psicanálise, da teologia e da teoria social; a poética histórica, a axiologia (teoria crítica dos conceitos de valor) e a filosofia da responsabilidade.

Bakhtin, assim, transitou por várias fases $\mathrm{e}$ abordagens que se refletiram em suas obras, conforme descreveram Clark \& Holquist (1984):

1. Fase filosófica, metafísica (aproximadamente entre 1918 e 1924): sob forte influência de pensadores do neokantismo e da fenomenologia;

2. Fase de diálogos críticos junto à teoria freudiana, marxismo soviético, formalismo e a linguística (entre 1925 e 1929);

3. Fase de busca da poética histórica (durante os anos de 30);

4. Volta à metafísica a partir da teoria social e da filosofia da linguagem (nas décadas de 60 e 70).

Apesar de todas as suas fases, o que nos interessa, sobretudo, nesse pensador é a construção epistemológica que gira em torno da responsabilidade e do lugar do Outro. O autor começa a elaborar sua filosofia da responsabilidade em 1919 ao produzir o artigo Arte e Responsabilidade, que 
só viria a ser publicado uma década depois. Bakhtin, então, nos anos de sua juventude, quando, em 1920, leciona Literatura e História da Filosofia da Música (Sampaio, 2012), escreveu os textos $O$ autor e o Herói e Para uma filosofia do ato, nos quais dá continuidade ao seu projeto de constituir uma arquitetônica em torno da vida, da arte e da ciência, integrando o ético, o estético e o cognoscitivo. Uma arquitetônica da Responsabilidade é, sobretudo, essa arquitetônica que nos interessa.

Seria talvez impróprio reconhecer em Para uma filosofia do ato uma escrita, por assim dizer, que se restrinja apenas à responsabilidade. Vai muito além. Porém, por se tratar de um dos textos mais germinais da escrita bakhtiniana (Faraco, 2003), essaobra apresenta noções fundamentais e que percorrem todos os posteriores escritos do filósofo russo acerca da responsabilidade. Psicológico, filosófico ou ético, o que nos importa é a força hermenêutica que as noções ali prefiguram sobre as questões ontológicas do ser, em especial, aquelas que respondem ao ato ético frente ao Outro. Aliás, a unicidade é que é o tema de mais intenso efeito nessa obra, donde decorre uma série de consequências acerca da responsabilidade e dos modos de ser. Preocupado com as dicotomias estabelecidas pelo sujeito epistêmico, tais como mundo da cognição teórica e mundo da vida; pensamento e realidade única e concreta, Bakhtin problematiza sobre a restauração dessas dualidades na unicidade responsável das ações de um ser que é radicalmente histórico; efeito de um evento espaço-temporal; reativo e, por isso mesmo, vivo.

Historicamente, o Ser único real é maior e mais pesado que o Ser unitário da ciência teórica, mas essa diferença em peso, que é auto-evidente para uma consciência viva que a auto-experimente, não pode ser determinada em categorias teóricas. (Bakhtin, 1993, p. 26)
Seria, assim, a partir do alheamento ético-histórico estabelecido por meio das ciências modernas (século XIX e XX), que o autor denuncia e deflagra sua narrativa sobre a impossibilidade da abstração configurada em disciplinas do saber, em dar conta da vida da ação, da vida viva. A racionalidade instrumental economicista impõe o império do logos, do científico-tecnológico. Portanto, o científico-tecnológico se torna um exemplo de um saber que, em sua autonomia de leis internas e de desenvolvimento “impetuoso, infreável” (Bakhtin, 1993, p. 25), se esquiva de sua maior tarefa, a saber, acompanhar seu desenvolvimento na cultura e aquilo a que ela se prestaria, sendo utilizada muitas vezes "antes ao mal que ao bem" (Bakhtin, 1993, p. 25). Em suas palavras: “[o Ser teórico] não pode oferecer nenhum critério para a vida prática, a vida da ação, porque ele não é o Ser no qual eu vivo, e, se ele fosse o único Ser, eu não existiria" (p. 27). E não existiria, uma vez que seria por intermédio do Ser evento único, temporalmente determinado, que as verdades das ciências respondem, alimentam-se e consistem como fato da existência.

O propósito bakhtiniano seria, necessariamente, a retomada da unidade inescapável do que existe no mundo, enquanto algo indissolúvel da eventicidade da existência do Ser, portanto. Assim, nesse pensamento, o ato teórico deveria encontrar-se incluído como ação real da vida do Ser - numa relação de necessidade moral e responsável. A razão teórica faria parte, como apenas um de seus momentos, da razão prática da vida, marcada pela unicidade das ações, participativas, afetivo-volitivas, singulares e concretas do mundo.

A dita "estetização da vida", ou ainda, "a vida-em-processo-de-devir" fariam parte do "sujeito portador do ato de visão" (Bakhtin, 1993, p. 31), sendo o objeto estético uma parcialidade que marcaria inescapavelmente a incompletude humana. 
Parcialidade porque esse ato de visão não pode ver tudo, é limitado pela posição corpórea, espaço-temporal, daquele que contempla. Em suas palavras:

\begin{abstract}
A tentativa de encontrar-se a si mesmo no produto do ato-ação da visão estética é uma tentativa de lançar-se no não-Ser, uma tentativa de abandonar tanto minha auto-atividade do meu lugar próprio e único situado do lado de fora de qualquer ser estético, quanto sua plena realização enquanto Ser-evento. $\mathrm{O}$ ato realizado da visão estética se eleva acima de qualquer ser estético - um produto deste ato - e é parte de um mundo diferente: ele entra na unidade real do Ser-evento, incorporando no Ser também o mundo estético, como um momento constituinte. A pura empatia seria, de fato, uma queda do ato-ação em seu próprio produto, e isso, é claro, é impossível (Bakhtin, 1993, p. 34).
\end{abstract}

No contexto dessa citação, Bakhtin enfatiza o impossível da transposição/anulação da lei da localização do Ser. Significa dizer que seria da ordem da radical impossibilidade do olhar se descolar da posição única que o contemplador assume no mundo (no instante real e concreto de ver) - numa fantasiosa busca de uma neutralidade extramundana/sobre-humana - que o produto do ato de visão dar-se-ia.

Numa de suas escritas posteriores, "O autor e a personagem na atividade estética" (1923/2003), Bakhtin problematiza sobre como se daria a contemplação da própria vida do autor na construção de uma escrita autobiográfica. Para abarcar esse problema, à luz da indissolúvel unicidade pela qual nos é possível experienciar e criar o mundo com suas alteridades, Bakhtin lança mão de noções como transgrediência e excedente de visão. Assim, o filósofo caracteriza o princípio fenomenológico nestes termos:
[...] essa posição singular, a única de onde se pode perceber o todo da personagem e o mundo como algo que de fora o guarnece, restringe e acentua, fora da personagem não é atingida de modo convincente e sólido pela visão do autor em toda a sua plenitude e daí, resulta, aliás, a seguinte peculiaridade do todo artístico característica desse caso: o fundo, o mundo às costas da personagem não foi elaborado nem é percebido nitidamente pelo autor-contemplador, e é dado supostamente, de modo incerto, de dentro da própria personagem, assim como é dado a nós mesmos o fundo de nossa. vida (Bakhtin, 1993, p. 17)

O dito fundo da nossa vida, o que fica às nossas costas, é suposto, imaginado ou, ainda, criado, a partir da unicidade do ato de visão do autor; num exercício de pretensa exotopia. Um deslocamento operado na posição do sujeito, para a qual este se projeta sobre o olhar de um outro imaginário, uma alteridade indeterminada, mas que se prestaria a apreender a dimensão transgrediente do ângulo de visão da consciência do autor. Buscando tornar-se um outro em relação a si mesmo (eu-para-os-outros), tenta-se espreitar os pontos-cegos, o desconhecido; a refração projetiva do que nos escapa e, por isso mesmo, é dotado do mais intenso valor.

A estilística existencial ou, ainda, a estetização da vida seriam fortemente marcadas pelo movimento de inatingível captura do que nos ultrapassa, excede-nos através do olhar de um estranho que nos habita. A autoria, nessa concepção, construir-se-ia no movediço solo de uma posição sustentada na tensão entre a transgrediência valorativa (axiológica) e os destinos narrativos que produzimos para os indeterminados efeitos deste radical ${ }^{3}$ espelhamento através dos olhos dos Outros. Para Clark e Holquist (2004, p. 97), "self, uma atividade que nunca posso completar. De modo que o self tem de ser pensado como um projeto".

\footnotetext{
${ }^{3}$ O termo radical é utilizado no sentido de raiz constitutiva do processo de subjetivação.
} 
O objeto estético sempre traria a marca daquele que o produz em sua ação contemplativa, assim como seria dessa condição que desliza a responsabilidade do contemplador sobre aquilo que vê. Para o referido filósofo, compreender um objeto é, sobretudo, compreender o dever do sujeito-contemplador em relação a ele, compreendê-lo em relação à unicidade do meu Ser-evento. Isso nunca enquanto uma abstração de si mesmo, de sua posição, mas, sobretudo, reconhecendo e assumindo os efeitos que podem ser produzidos nesse jogo de diferenças, nesse jogo fluido entre alteridades. Esse é um dos princípios que regem a própria formação humana.

Se entendermos que, nessa perspectiva, a ação é uma resposta, uma responsividade natural e própria do Ser que vive a partir de um infindável campo de contingências, vive e existe a partir de um mundo de mutáveis e evanescentes estímulos, perceberemos que o "eu" não adquire consistência "em si mesmo", fora de um ethos, de uma ambiência. É como um contínuo de responsividades particulares a um meio que seria da mais intensa mutação (física, temporal, histórica, discursiva, organísmica) que nos tornamos sujeitos plenos de vida. Conforme propõe Clark e Holquist (2004, p. 93), o self seria "uma dádiva do outro".

Torna-se importante assinalar que a dádiva supracitada não deve ser significada como algo passivamente recebido, mas como evento vividamente participado.

Tudo o que tenha a ver comigo me é dado em um tom emocional-volitivo, porque tudo é dado a mim como um momento constituinte do evento do qual eu estou participando. Se eu penso em um objeto, eu entro numa relação com ele que tem o caráter de um evento em processo. Em sua correlação comigo, um objeto é inseparável de sua função no processo. Mas essa função do objeto dentro da unidade do evento real que nos abrange é o seu valor real, afirmado, isto é, é o seu tom emocional-volitivo (Bakhtin, 2010b, p. 51).
Nesse sentido, participar implica a inevitável responsividade proativa do Ser naquilo que ele experimenta como dado. O Ser que se constitui entre o lócus único de sua responsividade vital e o ambiente alteritário (natural e cultural) do qual faz parte, autora na sensibilidade pela qual apreende o Outro. O tom emocional-volitivo no texto bakhtiniano parece aludir à realidade encarnada, entoada nas palavras enunciadas pela alteridade, $\mathrm{o}$ que performatizaria tudo aquilo que excede e, ao mesmo tempo, torna-se indissolúvel do universo semântico por meio do qual existimos. No que se refere, portanto, à proatividade do vivido, Bakhtin, todavia, adverte:

[...] eu posso ignorar minha auto-atividade e viver apenas pela minha passividade. Eu posso tentar provar meu álibi no Ser, eu posso pretender ser alguém que não sou. Eu posso abdicar da minha obrigatória (dever ser) unicidade. Um ato ou ação responsável é precisamente aquele ato realizado sob a base de um reconhecimento de minha obrigatória (dever-ser) unicidade. É essa a afirmação do meu não-álibi no Ser que constitui a base da minha vida sendo tanto real e necessariamente dada como também sendo real e projetada como algo-ainda-por-ser-alcançado. É apenas o meu não-álibi no Ser que transforma uma possibilidade vazia em um ato ou ação responsável e real (Bakhtin, 2010b, p. 60)

O não-álibi no Ser parece realçar a dimensão ética das proposições bakhtinianas. Essa noção, central ao texto, reitera a preocupação sobre os efeitos da ação criativa, implicando a filosofia moral de Bakhtin, a consequência inescapável da unicidade da existência. O algo-ainda-por-ser-alcançado deflagraria o permanente "porvindouro" das ações, num movimento de tensão ante a responsabilidade e a constante invenção de si (Arte e responsabilidade, 2010). Assim, esse filósofo também tenta diluir qualquer entendimento do Ser como unidade, indi- 
vidualidade, centro ou núcleo egoico. O Ser, movido e constituído por meio de infinitas alteridades, não seria encontrável por ele mesmo. Em suas palavras: "O fato de minha participação única e insubstituível no Ser é entrar no Ser precisamente onde ele não coincide com ele mesmo: entrar no evento em processo do Ser." (Bakhtin, 2010b, p. 60).

$\mathrm{O}$ arcabouço teórico oferecido por Bakhtin nos direciona à infinita e inevitável relação ética com a alteridade. Dessa forma, assim como Lévinas, essas filosofias devem ser amplificadas no pensar e no agir da Educação Ambiental, engajada numa gramática não logocêntrica, crítica do tecnicismo e da objetificação da alteridade não humana. Isso dado que as modalidades hermenêuticas das relações do Eu mesmo com o não Eu nos abre em direção da constituição de um sujeito dialógico e que balize sua relação com o mundo, numa relação eticamente responsável e ciente do não álibi do ser.

Pode-se observar que tanto em Bakhtin quanto em Lévinas não encontramos uma elaboração específica sobre a dualidade humano-não humano, conforme discutido na introdução deste artigo. No entanto, aposta-se nesses autores, uma vez que suas considerações sobre a alteridade, no sentido mais amplo, permitem perspectivarmos as tensões e responsividades éticas implicadas na relação junto ao não eu humano e não humano, como no caso da natureza em sua alteridade fundamental, intangível e irredutível aos sentidos emprestados pela humanidade em suas refrações históricas e ideológicas. Sendo assim, ainda que reconheçamos a intransponibilidade da unicidade do eu no mundo (é impossível sair da linguagem para contemplar a realidade pura), por outro lado, esses filósofos nos induzem a pensar não apenas na cogênese da alteridade da constituição do 'eu mesmo', mas também no papel de nos deslocarmos em direção ao outro, num exercício utópico, como forma de atingir aquilo que seria dotado de maior valor na vida, a saber: o transgrediente de visão, nossos pontos cegos, princípio estético e ético da diferença.

\section{Da articulação dos pontos de contato entre Lévinas e Bakhtin às contribuições para uma Educação Ambiental}

Tendo em vista que o presente artigo tem por objetivo apresentar como as categorias ora destacadas e seus modos de expressão no pensamento de Lévinas e Bakhtin podem suscitar contribuições para a Educação Ambiental (EA), chega-se, por fim, ao momento de discuti-las.

Antes de tudo, é necessário fazer um esclarecimento, o de que a EA, como a concebemos, não se trata de uma célula, uma disciplina isolada com um currículo fechado e sem conexão com outros saberes, mas de uma educação que nos leve, no universo do conhecimento, em direção à:

revolución copernicana del saber. Pero esta vez, el descentramiento del mundo no va de la Tierra hacia la inmensidad del Universo, sino del logocentrismo de las ciencias hacia el infinito de los saberes. Si antes de Copérnico el universo era un plasma oscuro e insondable, con la ciencia positivista los saberes otros fueron subyugados y extraditados hacia el espacio negro del no-conocimiento. Pero allí esperaban estos astros enceguecidos para iluminar, desde la ígnea e ignota fuente del saber ambiental un nuevo universo de saberes para derribar los muros de contención y abrir el cerco de las ciencias. La llama del saber ambiental, llama a pensar e inflama el pensamiento con un deseo de vida, de un futuro sustentable. (Leff, 2010, p. 2).

Cabe esclarecer também que a EA que hoje vivenciamos atravessa uma encruzilhada, pois, como 
alertara Vallejos (2010), a insuficiente ${ }^{4}$ absorção das reflexões mais profundas na prática educacional, que poderiam ajudar na orientação dos processos de significação responsável do Outro, está contribuindo para a perda de confiança e credibilidade do que esta transmite. Essa situação suscita a necessidade de fortalecer a EA em sua linhagem ético-moral.

Apesar da existência de um bom número de trabalhos com uma noção de EA mais profunda e filosoficamente próxima das bases da alteridade (Grün,1996; 2002; 2003; 2005; 2007; Layrargues, 2002; Leff, 2004; Carvalho et al., 2008; 2009; 2011; Carvalho, 2010), a prática da EA aparenta ainda guardar marcas da perspectiva tecnicista e simplista. Uma das questões centrais dentro dessa problemática é a convicção de que a formação dos indivíduos, ao longo dos dois últimos séculos, foi se impregnando cada vez mais de conteúdos científico-tecnológicos em detrimento de outros conteúdos preocupados com a economia-política e muito menos com a alteridade e o Infinito ético (Ortega \& Mínguez, 2001; Duch, 1997; Mèlich \& Boixader, 2010). Dessa forma, a educação se coloca como mais uma dentro de uma estrutura de contínua vigilância e regulação simbólica e política dos indivíduos, como alertara Foucault (1996). O que temos é uma noção de educação produto de um processo de cerceamento político, moral, policial, empírico e científico do indivíduo, com o intuito de torná-lo integrado à sociedade moderna e à racionalidade instrumental. A vertente tecnicista da EA, por sua vez, o faz de uma maneira ambígua, utilizando-se da retórica ecologista, para servir como mais uma nesse processo alienante e reificador do grande Outro. Nesse contexto, como alertara Layrargues (2002, p. 179):

[...] muitos programas de educação ambiental na escola são implementados de modo reducionista, já que, em função da reciclagem, desenvolvem apenas a Coleta Seletiva de Lixo, em detrimento de uma reflexão crítica e abrangente a respeito dos valores culturais da sociedade de consumo, do consumismo, do industrialismo, do modo de produção capitalista e dos aspectos políticos e econômicos da questão do lixo. E a despeito dessa tendência pragmática, pouco esforço tem sido dedicado à análise do significado ideológico da reciclagem, em particular da lata de alumínio (material que mais se destaca entre os recicláveis), e suas implicações para a educação ambiental reducionista, mais preocupada com a promoção de uma mudança comportamental sobre a técnica da disposição domiciliar do lixo (coleta convencional $\mathrm{x}$ coleta seletiva) do que com a reflexão sobre a mudança dos valores culturais que sustentam o estilo de produção e consumo da sociedade moderna.

Se admitirmos, portanto, que a EA que hoje predomina, como alertou Vallejos (2010), está necessitando atuar de outro modo, ao menos no que toca à dimensão ético-moral das pessoas, isso nos obriga a considerar que a ética não é algo complementar ou mesmo apenas um elemento a mais, entre outros possíveis, na educação. Acredita-se, porém, que a ética é um aspecto constitutivo de qualquer ação educativa, seja formal, informal ou como a queira denominar. Nesse contexto, compartilhamos

\footnotetext{
${ }^{4}$ Todo campo educacional é formado por uma diversidade de matrizes ético-epistemológicas fomentadas por práticas culturais, bem como pelo jogo de forças da arena de vozes teórico-metodológicas e políticas de um dado contexto. Nesse sentido, a vertente tecnicista da EA não é tomada como a única perspectiva, nem a majoritária, desse campo de saber. Muito pelo contrário, são sabidos os diversos esforços empreendidos para sua reconstrução (Grün,1996; 2002; 2003; 2005; 2007; Layrargues, 2002; Leff, 2004; Carvalho et al., 2008; 2009; 2011; Carvalho, 2010), esforços nos quais a presente escrita se insere. No entanto, tendo em vista a forte influência da tradição acadêmico-racionalista nas pedagogias ainda vigentes é que retomamos a questão do tecnicismo, no intuito de fortalecer uma transformação cultural mais ampla, conforme proposto por Vallejos (2010).
} 
da afirmação de Mèlich \& Boixader (2010, p. 37): "La ética es estructural a la relación educativa o, lo que es lo mismo, sin ética la educación queda reducida a puro adoctrinamiento". Na mesma direção, Vallejos (2010) afirma que a formação dos indivíduos só é educativa se se configura como resposta responsável à interpelação do Outro humano e não humano. E que, "Por tanto, educar es responder al otro y del otro, al otro que me interpela, que me demanda; por lo que, desde una perspectiva ética, educar es hacerse responsable del otro" (Vallejos, 2010, p. 47).

Ambiciona-se uma EA que preze pelo equilíbrio entre a formação ética e científico-tecnológica da pessoa. Que entenda que são duas dimensões inseparáveis da educação. Não se trata, porém, de propor uma abolição da ciência na formação do ser humano, mas apenas que não limitemos a formação do humano à dimensão do logos, pois o humano não é composto apenas pelo sujeito teórico. Contudo, devemos encarar essa dimensão do logos com certo cuidado, pois, como afirma Vaz (2001, p. 232):

Há um paradoxo profundo no fato de que a filosofia do logos tenha sido a filosofia da anulação do outro. $\mathrm{Na}$ verdade, a mais alta realização dessa filosofia, ou seja, o platonismo encontrou seu método e sua expressão precisamente no diálogo. Mas o que é significativo no diálogo platônico, como encontro das almas e sua salvação pela filosofia - essa essência da mensagem socrática-, é a submissão dos interlocutores ao logos, de tal sorte que a salvação oferecida pela filosofia reside, finalmente, no consentimento à Ideia, que o logos descobre através do diálogo. (Vaz, 2001, p. 232).

Sendo assim, podemos concluir que o logos já surge situado no Eu mesmo. A grande consequência desse autocentrismo será, como esclarece Estevam (2009, a anulação sistemática do Outro, que, relegado ao esquecimento e sonegado de sua dignidade, não terá reconhecida sua alteridade.Segundo Duarte (1988), deve-se reconhecer, também, que estamos imersos num sistema de linguagem que é conceitual e classificatório e que faz parte de um mundo em que a produção de conhecimento embasa nossas relações com esse Outro humano e não humano; que tem a reificação como um imperativo e que atenua a essência estética e ética do humano, pela qual o reconhecimento da distinção desse grande Outro se turva em nossa percepção. O que impera é uma sociedade do Eu mesmo e do logos.

Ademais, construiu-se simultaneamente a esse império do logos uma noção de liberdade que é pautada na determinação do Outro pelo Eu mesmo, por meio da tomada conceitual. Porém, contrariamente à postura filosófica moderna que se ancora nessa defesa do Eu mesmo e de sua liberdade, a filosofia de Lévinas e Bakhtin nos mostra a necessidade de ampliar uma educação que maximize a abertura para a alteridade, na qual o Eu mesmo é convocado à responsabilidade que funda o próprio sentido do humano. "O acolhimento de Outrem põe a minha liberdade em questão, instaura-se uma situação na qual o 'Eu' é 'de-posto' da sua condição de sujeito soberano, detentor do conhecimento e da verdade" (Melo, 2013, p. 77).

Roga-se, portanto, por uma justa atenção à dimensão ética na EA. "Si educar hoy se resuelve en aprender ciencia para la búsqueda del mejor conocimiento y su aplicación en la solución de problemas concretos, también educar es aprender a ser-con-los-demás para mostrarse capaz de dar respuesta (responsable) de lo que hace." (Vallejos, 2010, p. 48). Assim, acreditamos ser necessário pensar e fazer a EA de um modo distinto, partindo-se, como propusera Vallejos (2010), da ideia de que a formação do sujeito primariamente se constitui em relações de dependência. Deve-se, nesse sentido, desvencilhar-se da maiêutica socrática e da 
tradição socrático-platônica, que induz que nada pode vir de fora, mas que tudo está, no fundo, já contido na alma, tornando nebuloso o destaque ao princípio alteritário do diálogo conforme discutido na presente escrita.

Para tanto, propomos que a EA ambiental se aproprie da ideia do Infinito de Lévinas, pois:

a ideia do infinito em mim, que implica um conteúdo que transborda o continente, rompe com o preconceito da maiêutica [...] um ser que recebe a ideia do Infinito - que recebe, pois não pode ter de si - é um ser ensinado de uma maneira não maiêutica, um ser cujo existir consiste na incessante recepção do ensino, no incessante transbordamento de si [...] (Lévinas, 2000, p. 181-182). ${ }^{5}$

Ou seja, uma EA que reconstrua a dependência do Outro humano e não humano. Uma dependência em relação à voz e ao rosto do Outro. Uma dependência dialógica. Para Bakhtin (2010a), seria a partir dessa relação dialógica que se geram e dinamizam as vozes, os valores e os significados, ou seja, é a partir de "uma construção dinamizada pela história de um povo, pela experiência dos falantes, pela unicidade do enunciador, pelas infinitas vozes sociais através das quais atribuímos sentido ao mundo" (Pinheiro \& Leitão, 2010. p. 99), no qual nós nos embasamos para tecer nossas relações com o Outro humano e não humano. É justamente essa possibilidade de ressignificação que entusiasma e preenche de esperança a "utopia" da superação da crise ambiental.

Por sua vez, a obra de Emanuel Lévinas, assim como a de Bakhtin, assume grande importância no atual contexto da discussão de uma EA que busque uma alteridade para superação da crise ambiental em questão, tendo em vista que a alteridade, ou seja, a transferência parcial de sentido ético do Eu para com o Outro humano e não humano, enfraquecida nas bases da modernidade, possibilita percepções, atos e relações de dignidade do Eu mesmo para com o Outro.

Ao estimular uma revisitação da obra léviniana, Souza (1999, p. 164) propõe que busquemos estabelecer a partir dela "uma antropologia por assim dizer 'não antropocêntrica', não 'egoísta' [...] A dignidade dessa antropologia se funda no Outro, e na indeclinável responsabilidade por este Outro." humano e não humano, com o objetivo de extrapolar a barreira perceptiva do mundo dualizado em ser e ente, em que só a relação humano-humano produz significado e é merecedora de restrições e atos eticamente responsáveis.

Cabe ressaltar que:

La relación de otredad no es la que se establece en la polaridad que produce el pensamiento metafísico en la dualidad mente-cuerpo, sujeto-objeto, unidad-diversidad. La relación con lo otro se da en el orden del ser y del saber; pero sobre todo es deferencia, relación ética con el otro humano [e não humano] y no una relación ontológica, epistemológica o fenomenológica. (Leff, 2003, p. 21)

Por sua vez, as preocupações com a ética e com o ato responsável com o Outro estão presentes, como vimos, também nos primeiros manuscritos de Mikhail Bakhtin, entre os quais destacamos Para uma Filosofia do ato (Bakhtin, 2010b), no qual afirma que

\footnotetext{
${ }^{5}$ O professor é o Outro do aluno e o aluno é o Outro do professor. Não se trata aqui de uma educação depositória, unilateral, pois o sujeito também é portador de saber. É um diálogo Infinito com alteridade dos saberes.
} 
A vida pode ser compreendida pela consciência somente na responsabilidade concreta. Uma filosofia da vida só pode ser uma filosofia moral. [...] Separada da responsabilidade, a vida não pode ter uma filosofia; ela seria, por princípio, fortuita e privada de fundamentos. (Bakhtin, 2010b, p. 117)

Assim, o reconhecimento de que não existem álibis no ser é o que nos leva de encontro ao ato responsável em que "o Outro é fundamental como condição de existência e de tomada de consciência do sujeito." (Knoll, 2013, p. 35). Portanto, o Outro e a responsabilidade com este Outro operam como ideias essenciais para que "a realidade possa se repousar na ética, ou se dê eticamente, ou trespasse a mera 'espessura ontológica' dos entes e do ser, à procura de um sentido ético para o ser e para os entes - e não apenas para o ser humano." (Souza, 1999, p. 165).

Essa busca de transformação da compreensão cosmo-ontológica do Universo se faz imediata na Educação Ambiental, pois se não a modificarmos radicalmente por uma compreensão fundamentalmente ética do Universo, a crise ambiental em questão pode ser ainda mais intensa. Desse modo, ainda devemos revisitar mais profundamente essas categorias, sob a égide de uma alteridade universal, ou seja, de uma compreensão do Infinito ético.

La construcción de un futuro sustentable implica pensar la apertura de la historia, el desujetamiento del orden cosificador y sobreeconomizador del mundo. Apunta hacia la creatividad humana, el cambio social y la construcción de alternativas. Es ello lo que lleva a pensar la apertura de lo mismo hacia el otro.(Leff, 2003 p. 14).

Sempre otimistas no que tange à superação da lógica da racionalidade instrumental economicista, criadora de uma armadura epistêmica e civilizatória atenuadora da alteridade e aparentemente impenetrável, encaramos a EA como uma possibilidade de transpassar a supremacia do logos e de ir em direção ao diálogo de saberes que se inscreve em uma política da diferença, a qual ultrapassa, como propõe Leff (2003), o sistema dos saberes existentes, constituindo-se no encontro com a alteridade. Sendo assim, não devemos embasar nossas relações com o Outro a partir da violência do conceito, pois esta aparenta aplicar uma força que lhe nega sua individualidade, ou seja, que apropria o Outro no Eu mesmo. Nessa perspectiva de EA“[...] la activación de la responsabilidad (decisión, acto, praxis) siempre tendrá lugar antes y más allá de cualquier determinación teórica o temática [...]"(Derrida, 1998, p. 26).

Entretanto, deve-se elucidar que a passagem do mundo produto da racionalidade instrumental para um mundo fruto do dialogismo, dos atos responsáveis e do encontro Infinito com a alteridade é uma tarefa, sobretudo, de ressensibilização do ser humano.

Por conseguinte, devemos pensar uma EA que conduza à desconstrução das lógicas de conhecimento e de poder dominantes, abrindo as vias, como propõe Leff (2003), para outras ressignificações da Natureza, e possibilitando, por intermédio da linguagem e das novas estratégias de apropriação da natureza, novas modalidades hermenêuticas e estéticas da relação com o Outro.

\begin{abstract}
A educação, que primou pela sistematização do mundo, hoje precisa ensinar o ser humano a reencontrar-se com o mundo, à misturar-se à natureza e repensar suas necessidades. [...] sua relação com o mundo e com o outro. O ser humano é emoção antes de razão e esse contato primordial com o mundo foi durante muito tempo negligenciado pelo processo educativo. (Marin \& Oliveira, 2005, p. 208).
\end{abstract}

Destarte, tencionando evitar que caiamos numa espécie de humanismo reduzido que não extrapole a dimensão das letras e dos bons intentos 
inerentes à realidade rígida e complexa das relações humano-humano e humano-não humano, este artigo chama a atenção, especialmente, para a necessidade de uma EA que busque a superação da crise ambiental. O que só se alcançará na medida em que a sociedade for, efetivamente, reeducada para se impactar com e pelo Outro. Isso porque não bastam belas ideias, mesmo que pródigas, sem correspondentes posicionamentos no enfrentamento das teses e das vontades que se confrontam para serem impostas. Portanto, buscamos chamar a atenção dos estudiosos da EA para escaparmos de uma atitude puramente teórica para se caminhar em direção, ao mesmo tempo, do comportamento humano em sua complexidade - sujeito teórico e prático.

Nesse sentido, reiteramos que emerge a necessidade de uma educação que delineie a ética como filosofia primeira, sobre a qual poderá erguer-se uma nova filosofia como filosofia do Outro e que considere a alteridade e a poética do mundo, como alertara Lévinas (2000) e Bachelard (1993). Nesse contexto, tem-se como imperativa a superação da dualidade posta entre o aspecto contemplativo da teoria do conhecimento e a atividade individual do sujeito ético marcada pelo domínio do objeto reificado, por meio da reconstrução do espírito humano, como alertara Mendes (2014), que permitiria o jogo entre as gramáticas do entendimento e da sensibilidade. O Outro, enquanto imperativo da ética como filosofia primeira, poderia, então, restabelecer a plenitude do humano, como propusera Bakhtin.

\section{Referências}

Amorim, M. Para uma filosofia do ato: "valido e inserido no contexto". In: Brait, B. (Org.). Bakhtin, dialogismo e polifonia. São Paulo: Contexto, 2009. p. 17-43.
Sendo assim, devemos encontrar na EA uma intercessão entre os contornos da sensibilidade e da razão; descobrir um alicerce objetivo entre o jogo do sentimento e do entendimento, da prática sensível e da razão; requerer uma nova ética e uma estética que associem, em seu conjunto, as potencialidades humanas, na direção do resgate da unicidade do humano. Unicidade aqui aberta à medida do infinito. Unicidade, porém, não como apresentada na unidade (totalidade) da ontologia heideggeriana, que, ao identificar pensamento e ser, tornou o pensar incapaz de abrir-se para a alteridade,mas como lócus originário da busca da inteligibilidade e do sentido. Aqui, o humano torna-se lócus de uma relação intersubjetiva edificada no diálogo aberto e no respeito incondicional à diferença do Outro, como alerta Souza (1999).

Com isso, decerto, o individuo interpelado pela EA procurará, permanentemente, pressionar de maneira mais efetiva os gestores públicos locais, a fim de os fazer enxergar, pela escuta das alteridades envolvidas, a complexidade dos problemas ambientais inerentes de seus respectivos territórios. Sem tal consideração, não se conseguirá avançar mais.

Espera-se, portanto, que esse modo de se conceber a alteridade venha a fortalecer a dimensão ética da EA,ou seja, uma alteridade que se apresenta como a responsabilidade que assumo, sem álibi com o ato de meu pensamento e sem esquivança com o Outro (rosto), o qual não posso rejeitar, já que a minha própria condição de ser está em interdependência com a minha responsabilidade com ele.

Bachelard, G. A. Poética do espaço. São Paulo:Martins Fontes, 1993.

Bakhtin, M. Para uma filosofia do ato. Tradução não publicada de Carlos Alberto Faraco e Cristóvão Tezza, 1993. 
Bakhtin, M. O autor e a personagem na atividade estética. In: Bakhtin, M. Estética da criação verbal. 4. ed. São Pauto: Martins Fontes, 2003. p. 3-90.

Bakhtin, M. Arte e responsabilidade. 5. ed. São Paulo: WMF Martins Fontes, 2010a.

Bakhtin, M. Por uma filosofia do ato. São Carlos, SP: Pedro \& João Editores, 2010b.

Bøe, T. D. et al. Change is an ongoing ethical event: Levinas, Bakhtin and the dialogical dynamics of becoming. Australian and New Zealand Journal of Family Therapy, 34(1), 18-31, 2013.

Bussoletti, D.; Molon, S. I. Diálogos pela alteridade: Bakhtin, Benjamin e Vygotsky. Cadernos de Educação, 37, 2010. Disponível em: $<$ https://www.periodicos.ufpel.edu.br/ojs2/ index.php/caduc/article/view/1580>.

Capra, F.A teia da vida: uma nova compreensão cientifica dos sistemas vivos. 13. ed. São Paulo: Cultrix, 2006.

Carvalho, I. C. M.; Toniol, R. Ambientalização, cultura e educação: diálogos, traduções e inteligibilidades possíveis desde um estudo antropológico da educação ambiental. Revista Eletrônica do Mestrado em Educação Ambiental, 1, 28-39, 2010. Disponível em:<https://www.seer.furg.br/ remea/article/view/3393>.

Carvalho, I. C. M.; Grün, M.; Trajber, R. Pensar o ambiente: bases filosóficas para a educação ambiental. Brasília, DF: Ministério da Educação e Cultura, 2008.

Carvalho, I. C. M. et al. Paisagens da compreensão: contribuições da hermenêutica e da fenomenologia para uma epistemologia da educação ambiental. Cadernos Cedes, 29(77), 99-115, 2009. Disponível em: <www.scielo.br/scielo. php?script=sci_arttext\&pid=S0101-32622009000100007>.

Carvalho, I. C. M.; Farias, C. R.; Pereira, M. V. A missão "ecocivilizatória" e as novas moralidades ecológicas: a educação ambiental entre a norma e a antinormatividade. Ambiente \& Sociedade, 14(2), 35-49, 2011.

Clark, K.;Holquist, M. Mikhail bakhtin. Harvard University Press, 1984.

Clark, K.; Holquist, M. Mikhail Bakhtin. São Paulo: Perspectiva, 2004.

Derrida, J. Adiós a Emmanuel Lévinas. Palabra de acogida. Madrid: Trotta, 1998.
Duarte, J. F. Jr. Fundamentos estéticos da educação. 2. ed. Campinas, SP: Papirus, 1988.

Duch, L. La educación y la crisis de la modernidad. Barcelona, Paidós: 1997.

Erdinast-Vulcan, D. Between the face and the voice: Bakhtin meets Levinas. Continental Philosophy Review, 41(1), 43-58, 2008.

Eskin, M. Ethics and dialogue: in the works of Levinas, Bakhtin, Mandelshtam, and Celan. Oxford University Press on Demand, 2000.

Estevam, J. G. O reconhecimento da alteridade como possibilidade de construção de um novo paradigma na cultura ocidental em Joel Birman e Emmanuel Lévinas. Horizonte, 6(12), 169-179, 2009. Disponível em: <http://periodicos. pucminas.br/index.php/horizonte/article/view/446>.

Faraco, C. A. Linguagem e diálogo: as idéias lingüísticas do círculo de Bakhtin. Curitiba: Criar Edições, 2003.

Foucault, M. Vigiar e punir: história da violência nas prisões. Vozes, 1996.

Grün, M. Ética e educação ambiental: a conexão necessária. Campinas, SP: Papirus, 1996.

Grün, M. Hermenêutica, biorregionalismo e educação ambiental. In: Sauvé, L.; Orellana, I.; Sato, M. Textos escoIhidos em Educação Ambiental: de uma América à outra. v. 1. Québec: Les Publications ERE-UQAN, 2002. p. 91-99.

Grün, M. A outridade da natureza na educação ambiental. In:Reunião Anual da Associação Nacional de Pós-Graduação em Educação, 2003.

Grün, M. Gadamer and the otherness of nature: Elements for an environmental education. Human Studies, 28(2), 157-171, 2005.

Grün, M. Em busca da dimensão ética da educação ambiental. Campinas, SP: Papirus, 2007.

Knoll, G. F. A teoria dialógica de Bakhtin na análise da publicidade: sustentabilidade e ato ético. 2013. 199 f. Santa Maria, Tese (Programa de Pós-Graduação em Letras) - Universidade Federal de Santa Maria, 2013.

Latour, B. Políticas da natureza. Como fazer ciência na democracia. Trad. de Carlos Aurélio Mota de Souza. Bauru, SP: Edusc, 2004. 
Layrargues, P. P. O cinismo da reciclagem: o significado ideológico da reciclagem da lata de alumínio e suas implicações para a educação ambiental. In: Loureiro, C. F. B.; Layrargues, P. P.; Castro, R. S. de. Educação ambiental: repensando o espaço da cidadania. São Paulo: Cortez, 2002. p. 179-220.

Leff, E. Epistemologia ambiental. São Paulo: Cortez, 2001.

Leff, E. Racionalidad ambiental y diálogo de saberes: sentidos y senderos de un futuro sustentable. Desenvolvimento e Meio Ambiente, 7, 13-40, 2003. Disponível em: <revistas. ufpr.br/made/article/download/3042/2433>.

Leff, E. Educación ambiental: perspectivas desde el conocimiento, la ciencia, la ética, la cultura, la sociedad y la sustentabilidad. In: Anais del I Congreso Nacional de Educación Ambiental para el desarrollo sustentable de la Argentina, 2004.

Leff, E. La esperanza de un futuro sustentable: utopía de la educación ambiental. Sustentabilidades, 1(1), 2010.

Leff, E. Aventuras da epistemologia ambiental. São Paulo: Cortez, 2012.

Lévinas, E. Totalidad e infinito. Ensayo sobre la exterioridad. Salamanca: Sígueme, 1997.

Lévinas, E. Totalidade e infinito. Lisboa: Edições 70, 2000.

Lévinas, E. Entre nós: ensaios sobre a alteridade. Trad.: Pergentino S. Pivatto (Coord.). Petrópolis: Vozes, 2005.

Marin, A. A.; Oliveira, L. C. B. de. A experiência estética em Dufrenne e Quintás e a percepção de natureza: para uma educação ambiental com bases fenomenológicas. REMEA-Revista Eletrônica do Mestrado em Educação Ambiental, 15, 196-210, 2005. Disponível em: <https:// www.seer.furg.br/remea/article/view/2935>.

Mèlich, J. C.; Boixader, A. (Orgs.). Los márgenes de la moral: Una mirada ética a la educación.Barcelona: Graó, 2010.

Melo, E. A. Provocações sobre liberdade em Lévinas. Inconpidentia, 1(1), 2013.

Mendes, B.; Moretti, F.. A perspectiva da totalidade na reconstrução estética do homem em Schiller. In:Anais do X Seminário de Pós-Graduação em Filosofia da UFSCar. São Carlos: UFSCar, v. 10, 2014.

Mínjuez, R. V. La escuela hoy en la encrucijada. Hacia otra educación desde la ética de E. Lévinas. Teoría de la Educación, 22(2), 20, 2011.
Morin, E. Por uma reforma do pensamento. In: Pena-Vega, A.; Nascimento, E. P. O pensar complexo: Edgar Morin e a crise da modernidade. Rio de Janeiro: Garamond, 1999.

Morin, E. O Método I: a natureza da natureza. Porto Alegre: Sulina, 2013.

Muñoz, G. Principales tendencias y modelos de la educación ambiental en el sistema escolar. Revista Iberoamericana de Educación, 11, 13-74, 1996. Disponível em: <rieoei.org/ oeivirt/rie11a01.htm>.

Nealon, J. T. The ethics of dialogue: Bakhtin and Levinas. College English, 59(2), 129-148, 1997.

Ortega, P.; Mínguez, R. La educación moral del ciudadano de hoy. Barcelona: Paidós, 2001.

Passmore, J. Atitudes frente à natureza. Revista de Geografia, Recife: UFPE, 11(2), jul./dez. 1995.

Pelizzoli, M. L. A relação ao outro em Husserl e Levinas. Porto Alegre: Edipucrs, 1994.

Pelizzoli, M. L. Levinas: a reconstrução da subjetividade. Porto Alegre: Edipucrs, 2002.

Pelizzoli, M. L. Pensar a ética ambiental à luz da ética da alteridade. Perspectiva Filosófica, 1(19), 233-245, 2003. Disponível em: $<$ https://www.ufpe.br/ppgfilosofia/images/ pdf/pf19_artigo120001.pdf $>$.

Pena Vial, J. Lévinas y el olvido del otro. Scripta Theologica, 28(2), 543-564, 1996. Disponível em: < dadun.unav.edu/ bitstream/10171/13202/1/ST_XXVIII-2_06.pdf $>$.

Pinheiro, M.; Leitão, S. Bakhtin e a "vida dos outros". Revista Mal Estar e Subjetividade, 10(1), 87-110, 2010. Disponível em: <www.redalyc.org/articulo.oa?id=27116941005>.

Pivatto, P. S. Apresentação do livro. In: Lévinas, E. Entre nós: ensaios sobre a alteridade. Trad.: Pergentino S. Pivatto (Coord.). Petrópolis: Vozes, 2005.

Ponzio, A. A revolução bakhtiniana. São Paulo: Contexto, 2008.

Ponzio, A. Prefácio. In: Bakhtin, M. M. Para uma filosofia do ato responsável. Trad. Valdemir Miotello. São Carlos: Pedro \& João Editores, 2010.

Ramos, E. C. O processo de constituição das concepções de natureza. Uma contribuição para o debate na educação ambiental. Ambiente \& Educação, 15(1), 67-91, 2010. 
Disponível em: $<$ https://www.seer.furg.br/ambeduc/article/ view/905>.

Rodrigues, U. de M. Anarquia e subjetividade no pensamento de Emmanuel Levinas. Principios: Revista de Filosofia (UFRN), 18(30), 163-179, 2012. Disponível em: <https:// periodicos.ufrn.br/principios/article/view/1719>.

Sampaio, M. C. H. Ética e Ciências Humanas: diálogos filosóficos entre M. Bakhtin e E. Lévinas. Cadernos de Linguagem e Sociedade, 13(2), 185-206, 2012. Disponível em: <https://periodicos.unb.br/index.php/les/article/ view/7878>.

Sampaio, M. C. H. A propósito de Para uma filosofia do ato (Bakhtin) e a pesquisa científica nas Ciências Humanas. Bakhtiniana, 1(1), 42-56, 2009.

Sampaio, M. C. H. Vida e envelhecimento: uma re-leitura filosófica de Mikhail Bakhtin e Henri Bergson. In: Paula, L. de; Stafuzza, G. (Orgs.). Círculo de Bakhtin: Diálogos In Possíveis. São Paulo: Mercado das Letras, 2011. p. 101-122. (Série Bakhtin - Inclassificável, v. 2)

Sobral, A. Filosofias (e filosofia) em Bakhtin. In: Brait, B. (Org.). Bakhtin:conceitos-chave.São Paulo: Contexto, 2005. p.123-150.

Sorrentino, M. et al. Educação ambiental como política pública. Educação e Pesquisa, 31(2), 285-299, 2005. Disponível em: <www.scielo.br/pdf/ep/v31n2/a10v31n2.pdf>.
Souza, R.T. Sujeito, ética e história. Porto Alegre: Edipucrs, 1999.

Stevenson, L. Sete teorias sobre a natureza humana. Rio de Janeiro: Editorial Labor do Brasil, 1976.

Thomas, K. O homem e o mundo natural: mudanças de atitude em relação às plantas e os animais (1500-1800). São Paulo: Companhia das Letras, 2010.

Todorov, T. Prefácio à edição francesa. In: Bakhtin, M. Estética da criação verbal. São Paulo: Martins Fontes, 2011.

Tristão, M. A educação ambiental na formação de professores: redes de saberes. São Paulo: AnnaBlume, 2004.

Vallejos, R. M. La escuela hoy en la encrucijada. Hacia otra educación desde la ética de E. Lévinas. Teoría de la Educación, 22(2), 20, 2010. Disponível em: $<$ https://dialnet. unirioja.es/servlet/articulo? codigo $=3354475>$.

Vaz, H. C. L. Ontologia e história. São Paulo: Loyola, 2001.

Vial, J. P. Lévinas y el olvido del otro. Scripta Theologica, 28(2), 543-564, 1996. Disponível em: <http://cat.inist. fr/?aModele $=$ afficheN\&cpsidt $=3290888>$.

White, L. The historical roots of our ecologic crisis. Science, 155(3767), 1203-1207, 1967.

Zavala, I. O que estava presente desde a origem. In: Brait, B. (Org.) Bakhtin, dialogismo e Polifonia. São Paulo: Contexto, 2009. p. 151-166. 